\title{
RADIOLOGÍA E INFORMES RADIOLÓGICOS EN EL HOSPITAL DE SAN JOSÉ DE BOGOTÁ 108 AÑOS DE LA SOCIEDAD DE CIRUGÍA DE BOGOTÁ
}

Leonidas Borrero Borrero MD*

\section{Introducción}

Nos proponemos enmarcar en la historia del Hospital de San José los orígenes y evolución del servicio de Imágenes Diagnósticas, uno de los primeros que hubo en el país.

No es nuestra intención referirnos en extenso a episodios ya conocidos y estudiados como la fundación de la Sociedad de Cirugía de Bogotá, ${ }^{1}$ pero es necesario un acercamiento a la historia y al ambiente de la época para entender por qué a pesar de que el descubrimiento de los rayos X se remonta a 1895, sólo unos treinta años después pudo contar el Hospital de San José con este servicio imprescindible. El ambiente en el país no era favorable. Lo pone de presente el doctor Jorge Gómez C. en la edición especial del Repertorio de Medicina y Cirugía con motivo del Centenario de la Sociedad de Cirugía de Bogotá en el año 2002: "Circunstancias adversas rodearon a diez eminentes médicos que en los albores del siglo se reunieron en los salones del Club Médico el 22 de julio de 1902, para fundar la Sociedad de Cirugía de Bogotá. En ese año terminaba la Guerra de los Mil Días. La economía del país se encontraba en bancarrota, y todo estaba por hacerse en materia ambiental. No existían suficientes letrinas y alcantarillados...". ${ }^{2}$ Las condiciones del país no eran las mejores teniendo en cuenta que en la posguerra inmediata los fondos escaseaban y a pesar de la buena voluntad y de los deseos de los miembros de la Sociedad de Cirugía, el flujo de dineros debía adaptarse a las donaciones que se recibían. Ello originó que la construcción del hospital se realizara lentamente y por etapas y en medio de altibajos (Figura 1). Así lo expone el Dr. Darío Cadena Rey en el prólogo de: "Sociedad de Cirugía de Bogotá, Itinerario Histórico desde el 22 de julio de 1902". "La construcción del Hospital de San José fue obra de titanes. Se diseñó en grande, se programó majestuoso y se planeó importante. La ejecución del proyecto fue lenta, difícil, llena de angustias económicas, de incomprensiones, hasta de celos y de envidias". ${ }^{3}$ A lo dicho debe sumarse que cuando el país se recuperaba apenas de la guerra fratricida, estalló la Primera Guerra Mundial. Como si lo anterior fuera poco, el 1 de septiembre de 1932 la ciudad de Leticia fue ocupada por fuerzas peruanas y este hecho desencadenó un nuevo conflicto armado cuyas consecuencias son conocidas. Allí también estuvieron presentes la Sociedad de Cirugía de Bogotá y el Hospital de San José.

\section{Hospital}

Después de transcurridos muchos años plenos de "tantos sacrificios, largos de angustia", el 8 de febrero de 1925... "las puertas del Hospital de San José se abrieron de par en par para que por ellas entren todos los necesi- 


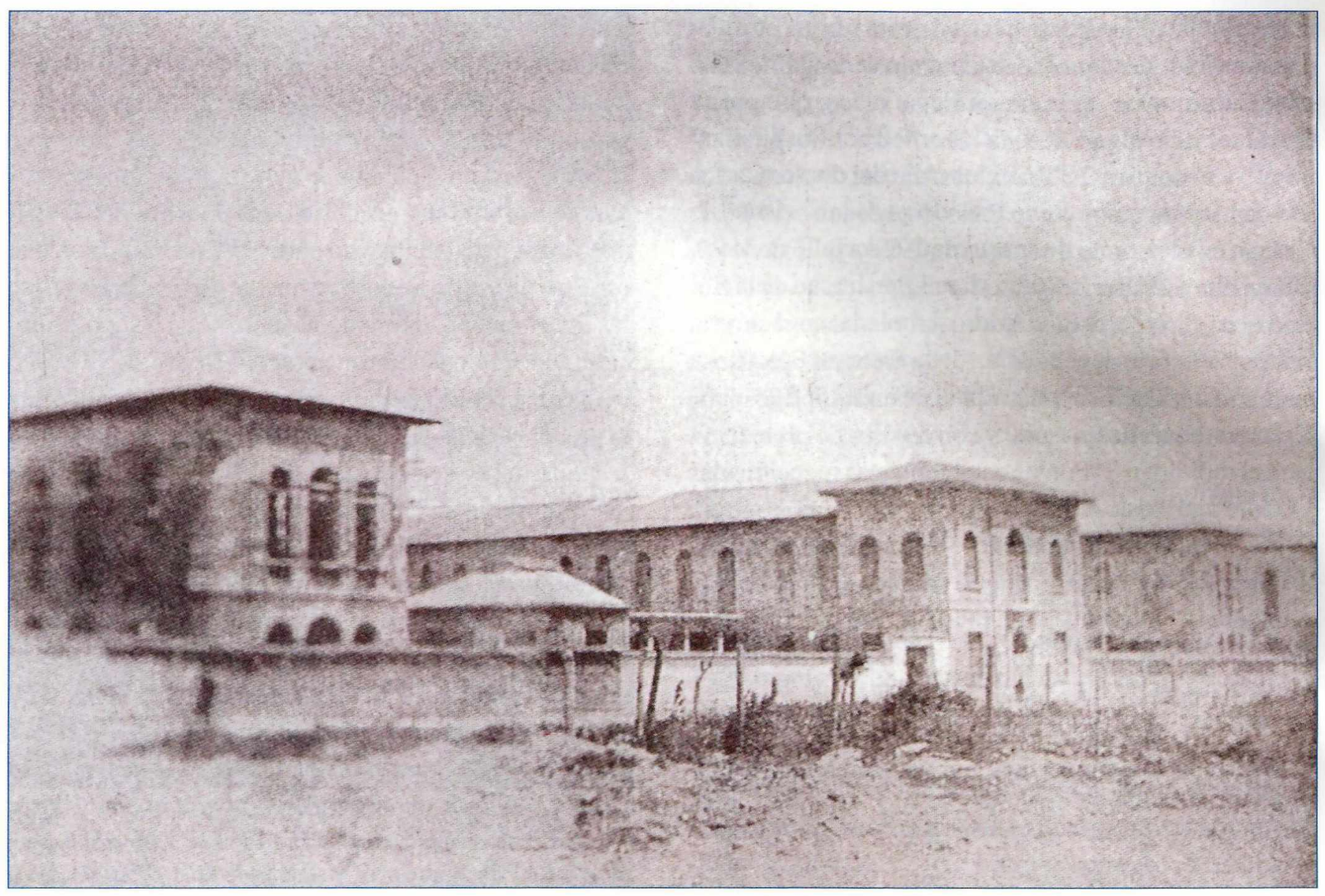

Figura I. Vista de la construcción del hospital hacia 1910 (foto archivo Hospital de San José).

tados..., todos los que sufran, todos los que necesiten consuelo"4. Este fue el acto que selló una apertura definitiva y solemne, pues con anterioridad (por ej. para atender a los afectados por una epidemia de tifo en el año de 1910) se habían dado al servicio diversos pabellones en forma gradual.

\section{Desarrollo del servicio de Radilología}

Si bien el profesor alemán Wilhelm Konrad Röntgen descubrió los rayos X en noviembre de 1895 cuando era director del Instituto de Física de la Universidad de Würzburg, sólo unos treinta años después pudo contar nuestro hospital con esta ayuda diagnóstica. A pesar de ello fue una de las primeras instituciones de la ciudad y del país que dispuso de esta clase de servicio.
Aun cuando no había inauguración oficial, el hospital (como ya se dijo) funcionaba de manera parcial desde hacía varios años. Fue en 1922 que gracias a una donación por valor de cincuenta mil pesos hecha por el acaudalado filántropo don José María Sierra, cuando se negoció y contrató con la Victor X Ray Corporation el equipo que había de instalarse en el laboratorio de rayos X del hospital en ese mismo año. Para dirigirlo "se contrató a Jorge E. Cavelier"'5 (es curioso que en ningún otro documento se vuelve a mencionar al Dr. Cavelier en relación con la radiología en nuestro hospital). Pero no faltaron las dificultades: aparte de que el señor Noble, técnico enviado por la casa matriz para poner en funcionamiento el equipo enfermó en Panamá, otros diversos problemas dificultaron la entrada en servicio en forma inmediata. En poco tiempo se instaló un primer equipo y para el año de 1922 ya funcionaba. Según se lee en la página 315 del libro del doctor L. Muñoz ${ }^{6}$ en el relato de la inauguración 
del hospital: ...."En la parte baja de ésta última edificación funciona, desde el año antepasado, la magnífica instalación de rayos X, la mejor de su clase, que presta eficaz servicio al público y a los enfermos hospitalizados..." y lo confirma: "En el Informe del doctor Carlos Tirado Macías, quien como Presidente de la Sociedad de Cirugía en el período de agosto de 1928 a julio de 1929 , refiere que en el período anterior el Presidente de la Sociedad de Cirugía, doctor Arturo Arboleda, negoció con la casa "Víctor", dependencia de la General Electric la compra e instalación en el hospital de un equipo de rayos $\mathrm{X}$ para radiografías en serie y con medios de protección para el radiólogo". ${ }^{7}$ Por las características mencionadas y la foto que existe de dicho equipo, concluimos que era en efecto de los más modernos y eficientes de la época (Figura 2). En 1926 se asignó sueldo al director y al ayudante del laboratorio de rayos $\mathrm{X}$, según el informe del doctor Julio Aparicio como Presidente de la Sociedad de Cirugía en el período 1926-1927. ${ }^{8}$

El primer encargado del denominado laboratorio de rayos X fue "el doctor Isaac Rodríguez, miembro de la
Sociedad de Cirugía y uno de los primeros médicos que en Colombia quiso dedicar sus actividades al ramo de la radiología"9 (Figura 3). En asocio con su hijo odontólogo Luis Rodríguez, comenzaron a prestar servicios tanto al hospital como al público en general. Algunos informes e indicios refieren que al uso de la época el Dr. Rodríguez instaló un laboratorio particular que habría sido el primero de esta modalidad o uno de los primeros que se instaló en la ciudad de Bogotá, pero no se ha podido encontrar documentación que pruebe este aserto. El hecho es que de acuerdo con los informes ya mencionados de la presidencia de la Sociedad de Cirugía para la época, se confirma que sí se instaló en el Hospital de San José un equipo en el año mencionado de 1922, que ya funcionaba en 1923 bajo la dirección del citado Dr. I. Rodríguez, que en enero de 1928 fue llamado el Dr. Enrique Otero a encargarse del laboratorio en asocio del Dr. Rodríguez y que hay memoria de que se asignaron sueldos al Director y al ayudante del laboratorio de rayos X. Además, en la inauguración definitiva del hospital el 8 de febrero de 1925 junto con diversos pabellones, salas de cirugía, servicios administrativos, ropería, cocina y otros,

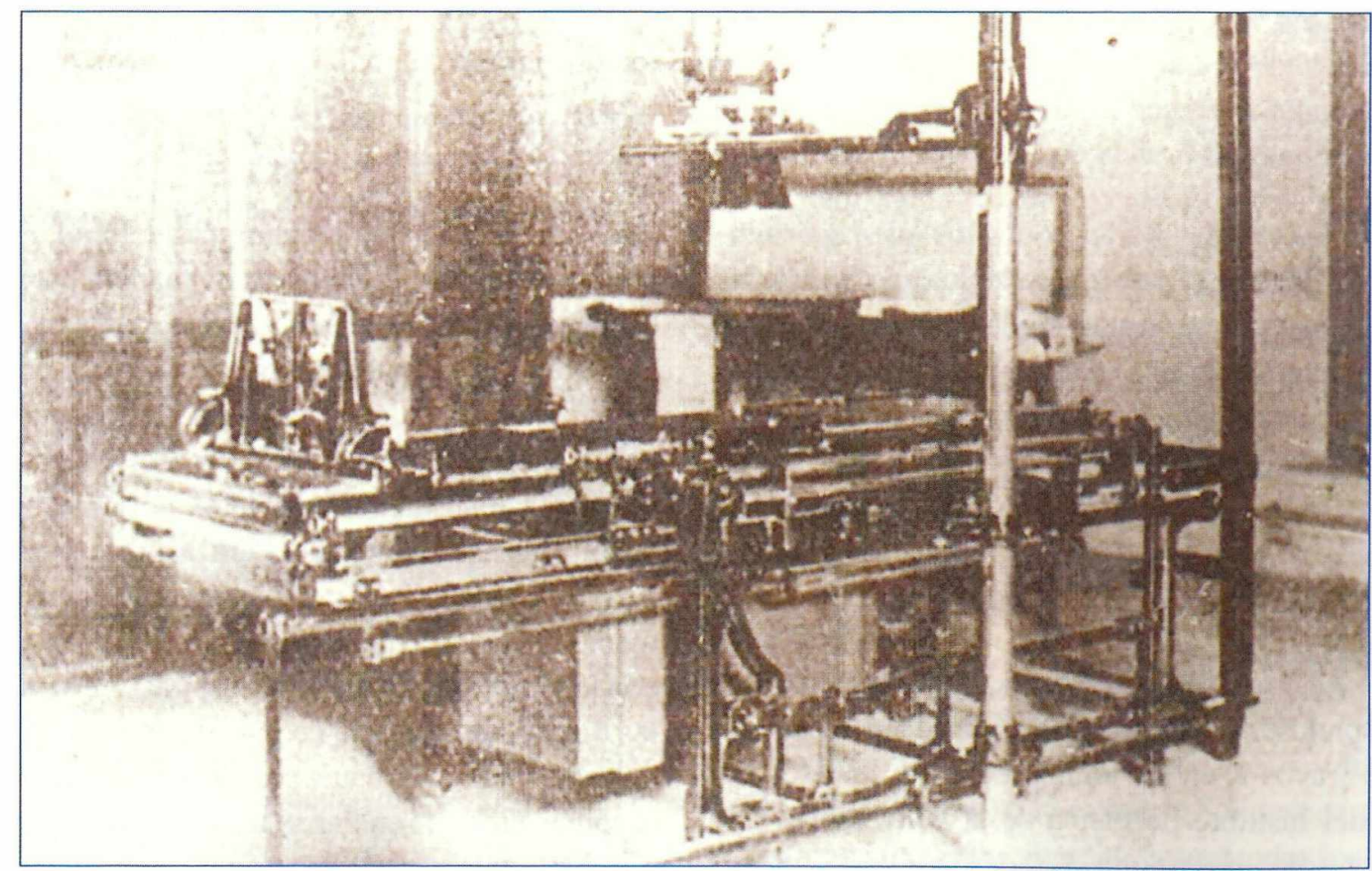

Figura 2. Fotografía del equipo de rayos $X$ adquirido por el Hospital de San José en 1922 y que funcionó en 1923. Apareció en el diario El Tiempo de Bogotá del 9 de febrero de 1925 y es una de las que ilustra la crónica de la inauguración (con permiso de la Sociedad de Cirugía de Bogotá, Itinerario Histórico desde el 22 de julio de 1902, p. 104). 


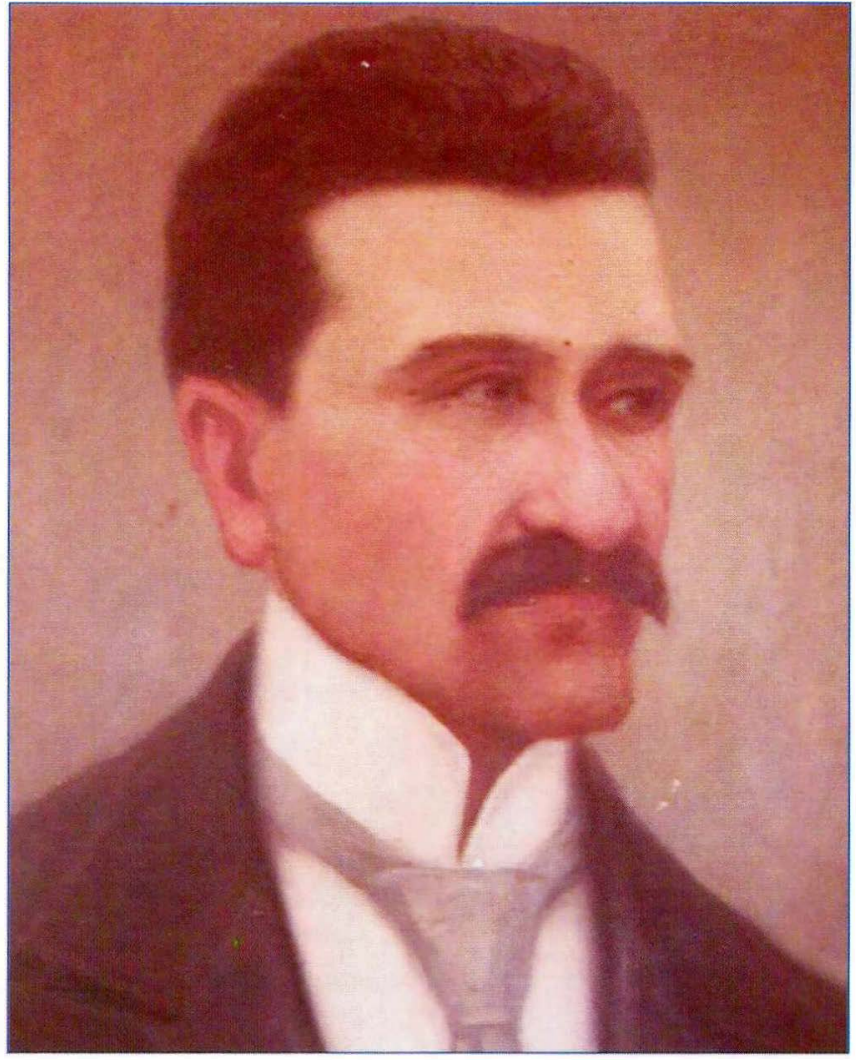

Figura 3. Retrato al óleo del Dr. Isaac Rodríguez, uno de los fundadores de la Sociedad de Cirugía, pionero de la radiología y primer director del servicio de rayos $X$ del Hospital de San José (foto archivo Hospital de San José).

inició el servicio de rayos $\mathrm{X}$ como lo hace constar uno de los fundadores de la Sociedad de Cirugía el doctor José M. Montoya en el Repertorio de Medicina y Cirugía: “...En la parte baja de esta última edificación funciona la magníficainstalación de rayos X". ${ }^{10}$

Por iniciativa del doctor Otero quien acababa de llegar deEuropa en donde había realizado estudios de especialización en radiodiagnóstico, se organizó un archivo y se llevaron las primeras estadísticas. Se abrieron libros en los cuales se anotaban los diagnósticos y algunos datos clínicos relativos a los pacientes. Permaneció en el cargo hasta 1948. ${ }^{11}$ Como vimos, en 1930 se retiró el Dr. Rodríguez por razones de salud y edad avanzada. Para esta época debieron vincularse al hospital los doctores Alfonso y Gonzalo Esguerra Gómez; éste último, nombrado desde febrero de 1920 secretario del laboratorio de radiología de la Facultad de Medicina de la Universidad Nacional ${ }^{12}$ aparece en una de las fotografías del cuarentenario de la Sociedad de Cirugía publicada en la página 363 del libro Historia del Hospital de San José 1902-1956, escrito por elDr. L. Muñoz, gozó de merecida fama en medios científicos nacionales e internacionales y falleció en Bogotá a fines del siglo pasado. Dados sus vínculos con la Facultad de Medicina y con la Clínica de Marly, su paso por el hospital no fue duradero. Los doctores Esguerra Gómez aparecen en los libros de la Sociedad de Cirugía en la categoría de Miembros Ausentes. En mosaicos del hospital figuran como adjuntos en el laboratorio de rayos X los doctores Eduardo Isaza Uribe (1936), Guillermo Sierra (1943) y Enrique Otero O., jefe del Servicio.

Otra anécdota del hospital y su aspecto humano es la referida por el doctor Muñoz ${ }^{13}$ acerca de un “...personaje que se hizo indispensable, omnipráctico, en el Hospital de San José...", Hans Perkins apodado el míster, de origen austríaco se radicó en Colombia en el siglo IXX y en 1929 ingresó al hospital según refiere en sus propias palabras, transcritas con su ortografía original: He entrado al hospital como paciente de enfermo de un ataque de apéndice, ... que me quedé en el hospital de Cirugía, como mecánico electricista técnico y supervigilante de obras en general. ...He servido en rayos $\mathrm{X}$, tomando radiografías de emergencia con aparato portable y estable y desarrollada de mismas. . ${ }^{13}$ El mismo señor Perkins aparece en la lista de donantes del Hospital 1902-1956 elaborada por el doctor L. Muñoz. Así pues, ya entonces contaba el hospital con por lo menos dos equipos, uno de ellos portátil.

Hemos mencionado que el doctor Enrique Otero estuvo al frente del laboratorio de rayos X hasta 1948 cuando se retiró después de más de veinte años continuos de trabajo dejando una nueva y moderna instalación "gracias al legado de $\$ 20.000$ que hubo de dejar la mortuoria del señor Gustavo Restrepo....", ${ }^{14}$ Se trataba de dos equipos General Electric de los cuales uno contaba con seriógrafo. El revelado de las placas se hacía en forma manual. Le sucedió el Dr. Carlos Perilla en los años cincuenta del siglo pasado y después el Dr. Marino Barona Pinillos estuvo al frente del servicio hasta 1960. No hay memoria de la fecha en que se trasladó el funcionamiento del servicio al segundo piso, pero para esta época se encontraba en la parte norte del Pabellón Central como se podía leer en la fachada que da cara al parque España (Figura 4), donde hoy 


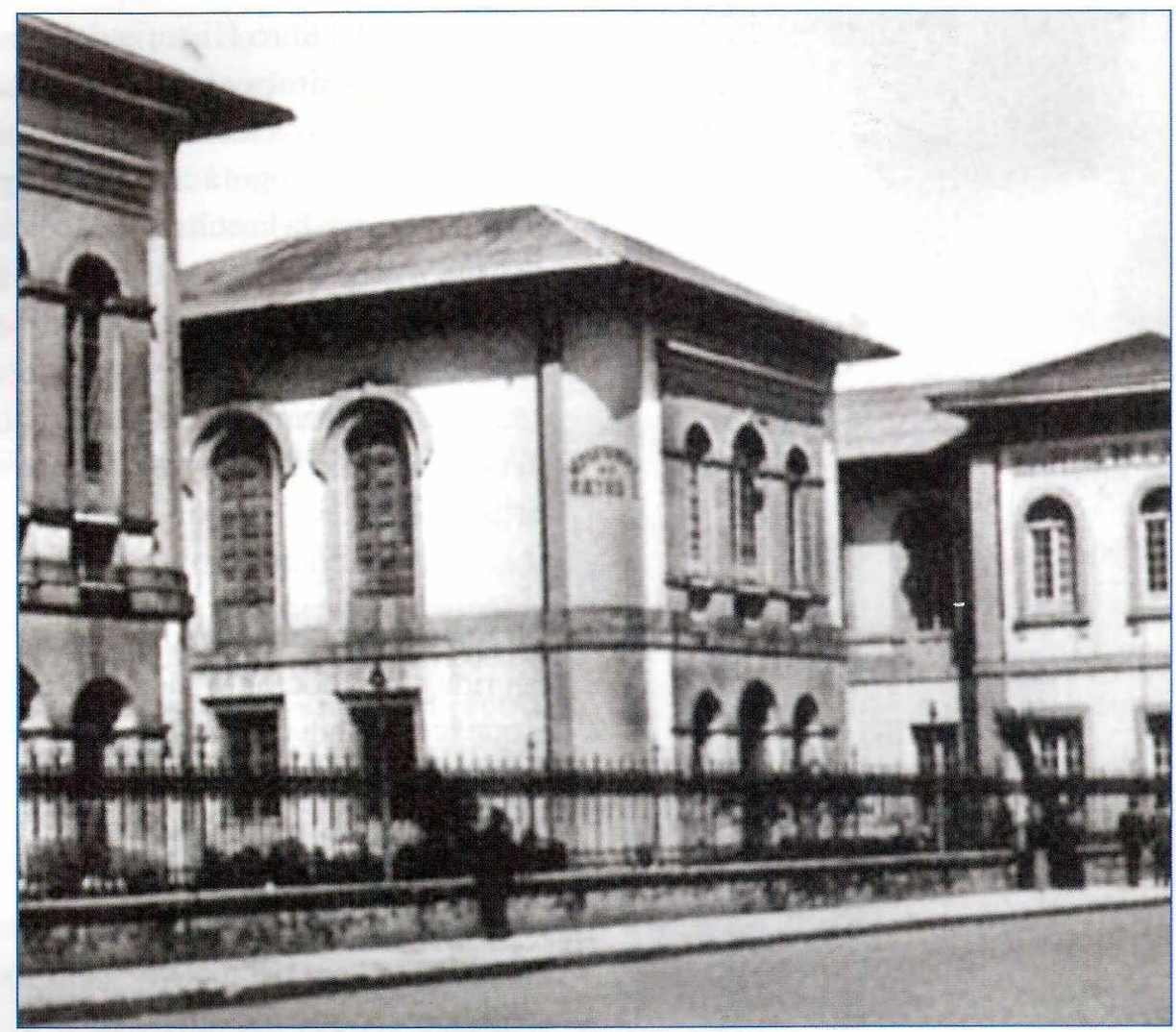

Figura 4. Fachada del Hospital de San José en la cual se puede leer la localización del laboratorio de rayos $X$ (foto archivo del Hospital de San José).

funciona el servicio de Hematología. Fungiendo como encargado de la jefatura del servicio el doctor Alberto Mejía Diazgranados, en un mosaico de la época aparecen como residentes de radiología los doctores Ernesto López Reyes y Jorge Rodríguez H.

A partir de 1960 y por espacio de 30 (treinta) años el Dr. Alberto Mejía Diazgranados (Figura 5) ${ }^{15}$ dirigió el Departamento y durante este tiempo se adquirieron diversos equipos que marcaron un hito pues se incorporaron a medida que se desarrollaban los adelantos médicos y científicos de la época. Así se dio comienzo a la actividad académica y bajo su dirección iniciaron su formación como residentes los doctores Luis S. Gómez y Antonio Guerrero en el año de 1960 y después siguieron sus pasos Jorge A. Sanz, José J. Suárez P., Hernando Morales G. y otros, en un proceso que ha dado prestancia al servicio y por ende al hospital. En 1966 se trasladó el servicio a la planta baja del nuevo edificio construido para albergar también la lavandería, salas de cirugía y el pabellón Fundadores entre otros.
Debe destacarse la estructura dada al servicio por el Dr. Mejía, no sólo con la adquisición de nuevos equipos sino con el desarrollo de subespecialidades gracias a la incorporación de profesionales como los doctores Hernando Morales G. quien al regresar de realizar estudios de perfeccionamiento en Londres introdujo métodos nuevos comolas arteriografías siguiendo el método de Seldinger, y el doctor Gustavo Sánchez S. neurorradiólogo formado en los Estados Unidos quien contribuyó al desarrollo de esta subespecialidad en Bogotá y en Colombia, y fue profesor de quien escribe estas líneas en los años ochenta del siglo pasado. El ingreso de estos especialistas llevó a la adquisición de equipos adecuados para la realización de cineangiografía con generador de 700 mA, cámara de televisión y de cine de $16 \mathrm{~mm}$ y de un seriador de la clase Sánchez Pérez diseñado para angiografía cerebral, el primero de su tipo que funcionó en el país. Los estudios angiográficos constituyeron una de las fortalezas de la institución, que se complementó con la adquisición de un seriador "Puck" programable Elema Schönander que mejoró la oferta de servicios de 


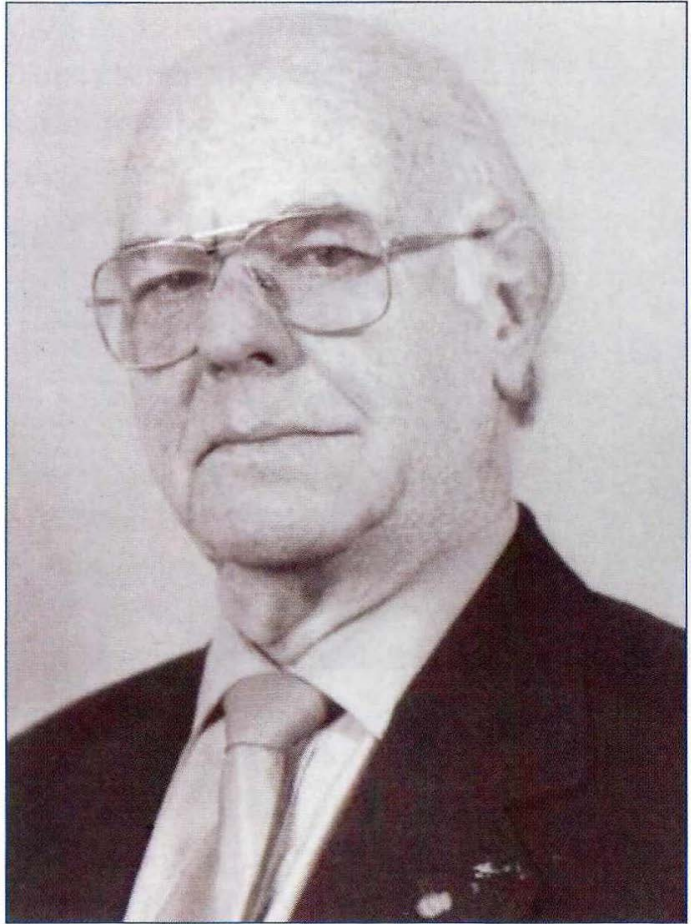

Figura 5. Dr.Alberto Mejía Diazgranados.

angiografías selectivas y superselectivas. Para esta época se iniciaron los primeros procedimientos de radiología intervencionista como embolización de tumores tales como nasoangiofibromas juveniles. No puede olvidarse tampoco la gran colaboración docente prestada por el Dr. Diomen Botero Palacio, quien fue también profesor de radiología de la Facultad de Medicina de la Universidad Nacional, en el Hospital de San Juan de Dios.

Hacia 1976 el servicio continuó a la vanguardia con los estudios de ecografía en el país, a cargo de la doctora Pilar Duque. Dada la importancia que adquirieron en el estudio de la patología ginecoobstétrica y abdominal, el éxito fue grande. Si bien por diversas razones, en especial de orden económico, el servicio de tomografía computadorizada sólo comenzó a funcionar en 1992 gracias al esfuerzo de empresarios particulares, médicos y directivas del hospital. Hoy cuenta con dos equipos modernos, uno de última tecnología de detectores que permite realizar en segundos estudios completos en todas las porciones del organismo. Se puede afirmar sin exagerar que hay más demora para acomodar al paciente para el estudio que en la realización del mismo.
Así, a pesar de limitaciones nuestra institución ha sido pionera en muchas ramas de las imágenes diagnósticas y sus aplicaciones. Ejemplo de ello fue la primera embolización selectiva de una malformación vascular arteriovenosa espinal realizada en el país, en conjunto con el servicio de neurocirugía, en 1990. Oel diagnóstico de un aneurisma de la arteria de Adamkiewicz (diámetro promedio 0,3- 0,4 mm), cuyaincidencia es tan baja que hasta 1992 cuando observamos esta patología tan solo había en la literatura científica informes de cuatro casos documentados. El nuestro era pues el número cinco (Figura 6). Esto, en medio de dificultades grandes como era la circunstancia de que la sustracción de las estructuras óseas para resaltar la angiografía era un procedimiento manual y artesanal. Hoy se realiza de manera automática en los equipos digitales.

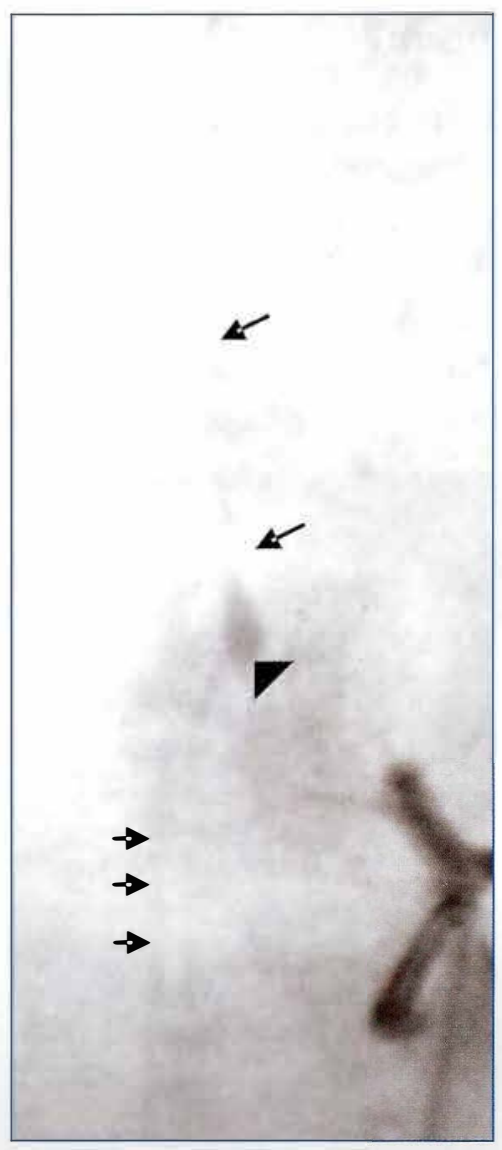

Figura 6. Angiografía espinal selectiva de la arteria de Adamkiewicz (flechas negras pequeñas) que muestra aneurisma de la misma (punta de flecha). La arteria espinal anterior está señalada por las cabezas de flechas pequeñas. Sustracción fotográfica manual. 
En 1995 se inauguró el servicio de resonancia magnética con el mejor aparato de la casa Siemens, el segundo de su tipo que se instaló en Suramérica con una intensidad de campo de 1,5 teslas y el primero con esta intensidad de campo que se instaló en el país. Permitió ir a la vanguardia de esta tecnología con estudios de gran calidad y colaborar en la formación de subespecialistas que se desempeñan en diversas instituciones, así como participar con numerosos trabajos en congresos de radiología, cirugía y neurocirugía entre otros. Desde su fundación fungieron como especialistas los radiólogos egresados del servicio de San José: Leonidas Borrero B, Mauricio Mejía J. y Jorge Fuentes Z., y el doctor John J. Hernán$\operatorname{dez} C$., neurocirujano rosarista con formación en resonancia magnética.Algunos logros muy importantes han sido los estudios de tumores con reconstrucción tridimensional (Figura 7) y el primer estudio funcional hecho en Colombia para un paciente que fue operado en el exterior (Figura 8).

Más de ochenta especialistas en radiología e imágenes diagnósticas han egresado producto de una escuela avalada por la Universidad del Rosario (a partir de 1972) y en la actualidad de la Fundación Universitaria de Ciencias de la Salud. Varios alumnos sucedieron al Dr. Mejía en la jefatura del servicio o nos vinculamos como espe-

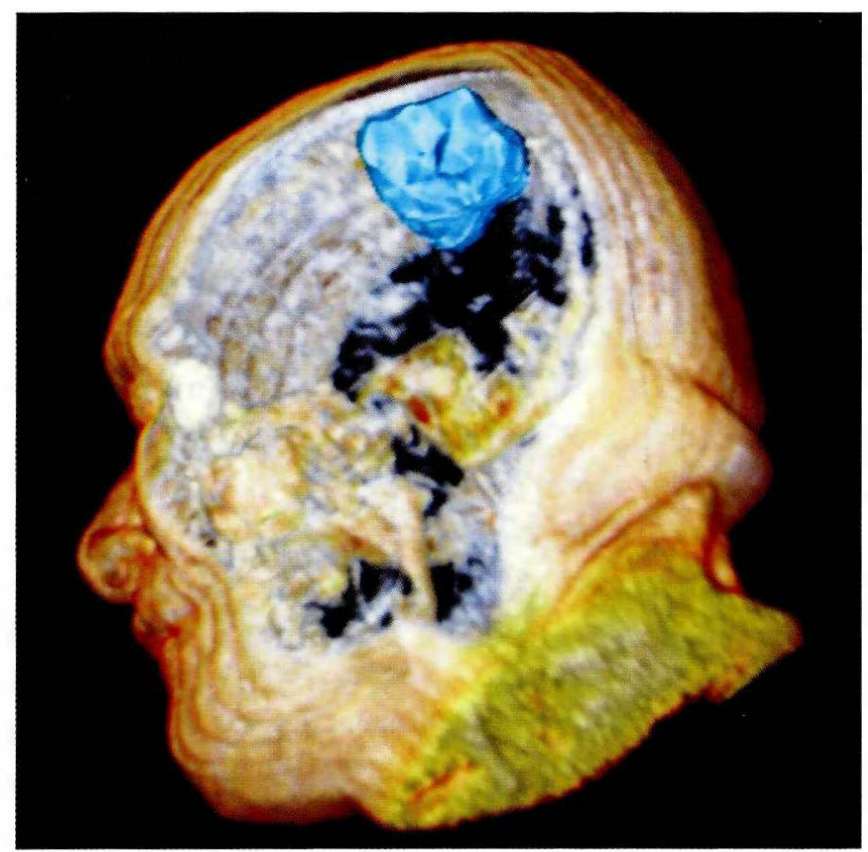

Figura 7. Reconstrucción tridimensional de un tumor parietal (en azul).

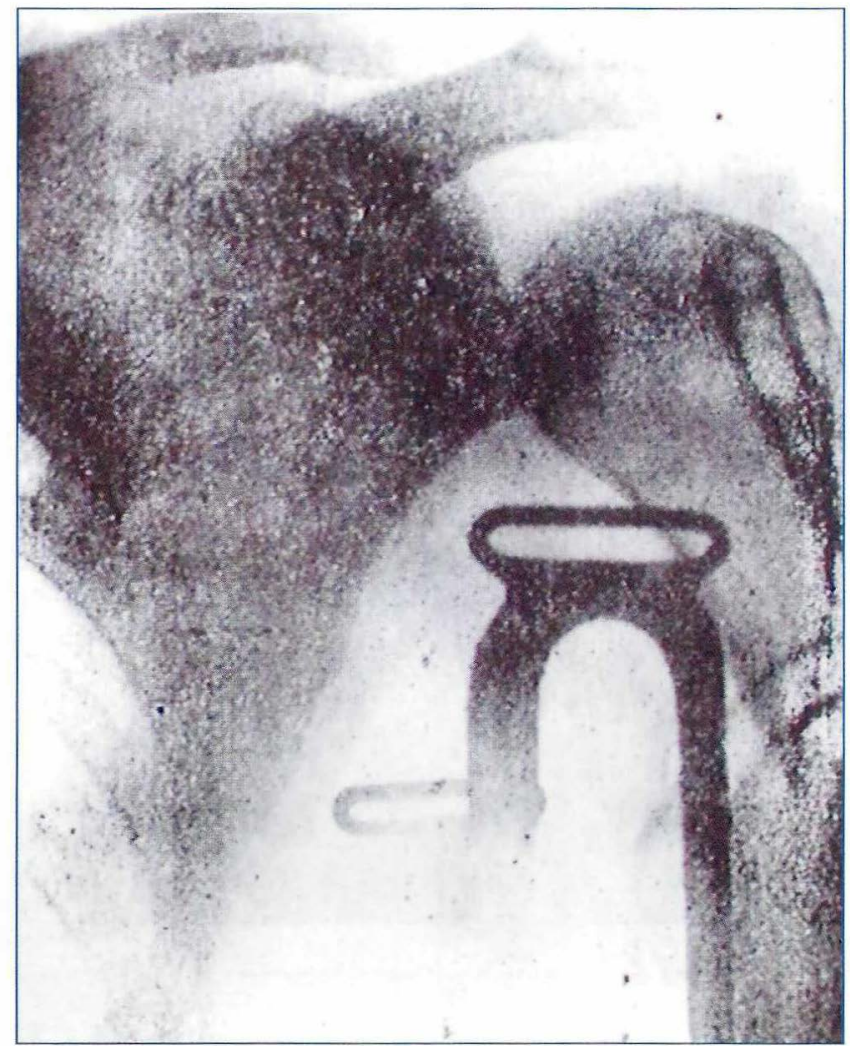

Figura 8: Fotografía de la primera radiografía que aparece publicada en Repertorio de Medicina y Cirugía, Vol.VIII No. 2 de noviembre de 1916, p. 250. No hemos encontrado radiografías publicadas con anterioridad en ninguna otra publicación nacional, así, ésta sería la primera en una revista científica en Colombia.

cialistas conformando un grupo que continuó su labor: José Joaquín Suárez P., Eduardo Molano M., René R. González, Martha L. Suárez M. y Leonidas Borrero Borrero, quien completó su formación como neurorradiólogo en el Hospital Universitario de Eppendorf de la Universidad de Hamburgo en Alemania. Otros exalumnos de San José son hoy jefes de servicios y personal científico de imágenes diagnósticas en numerosas instituciones del país y del exterior.

Profesores y alumnos de nuestro servicio han sido en diferentes ocasiones acreedores a diversos premios en certámenes nacionales e internacionales, haciendo honor a quienes nos precedieron y dando brillo a la imagen del hospital como institución pionera en la realización de estudios acordes con la tecnología y en la capacitación de especialistas. 
Pero no sólo se formaron médicos. De 1978 a 1983 funcionó una escuela para técnicos de radiología de la cual egresaron más de sesenta alumnos. Desde octubre de 2006 desempeña con éxito las labores un grupo conformado por especialistas de diversas escuelas que realizan con éxito una labor encomiable para mantener estándares de excelencia.

\section{Publicaciones}

Volvamos atrás en la historia puesto que las publicaciones científicas han estado unidas al desarrollo del hospital y por supuesto han tenido relación con la radiología en particular y lasimágenes diagnósticas en general. Los fundadores eran académicos y profesores, algunos de ellos vinculados a la Facultad de Medicina de la Universidad Nacional y a la Academia Nacional de Medicina cuyo órgano de divulgación era la Revista Médica de Bogotá. El doctor José M. Montoya uno de los fundadores de la Sociedad de Cirugía de Bogotá, graduado en la Universidad de Harvard, científico muy activo, fundó en 1909 el Repertorio de Medicina y Cirugía y fue su primer director.
La primera imagen de una radiografía la encontramos en la página 520 de la misma revista(Repertorio Medicina y Cirugía) ${ }^{16}$ en el Vol. VIII No. 11 de agosto de 1917 Número 95, en un artículo acerca del tratamiento de las fracturas, escrito por el doctor HT Buckner de Seattle, Washington.Aparece la fotografía de una radiografía del hombro izquierdo (Figura 8) fechada el 22 de abril de 1916 sin referencia al sitio en el cual se tomó la impresión radiográfica pero lo más posible es que se hubiera realizado en Seattle. Se refiere a un paciente del doctor Lisandro Leyva Pereira.

En esta revista en el Vol. VIII No. 8 de mayo de 1917 en las páginas 344-346 encontramos la primera referencia en un artículo científico titulado: "Rayos X en terapéutica y como elementos para el diagnóstico"17 por el Doctor Peer M. Lund de Bogotá, como se puede leer en el primer párrafo habla del descubrimiento y de la propiedad más notoria de los rayos X (Figura 9). El Dr. Lund, danés, fue el primer radiólogo contratado por la Facultad de Medicina de la Universidad Nacional de Colombia en Bogotá para organizar el gabinete y la docencia de la radiología en esa institución en 1917. ${ }^{18}$

\section{Valor cle lus rayos $X$ en terapsutica $y$ eorno elementos para el dirgnóstice}

POR EL DOCTUR PEKR M. I.UND

De Bogota

En estos tiempos en que se han intensificado y se han desarrollado tánto las investigaciones científicas no se encuentran muchos ramos de la medicina en el cual se haya progresado tánto y que se haya impuesto como elemento indispensable y se hayan logrado tảntas mej̧oñas ya. como agente terapéutico, ya como medio de diagnóstico que los rayos $X$. Y en los veinte y tantos años que han transcurrido desde que el doctor Roミntgen descubrió los asombrosos efectos de estos rayos, su aplicación se ha desarro-

Figura 9. Fotografía del primer artículo científico referente a los rayos $\mathrm{X}$, publicado en Colombia en la revista Repertorio de Medicina y Cirugía de la Sociedad de Cirugía de Bogotá, Vol.VIII No. 8 de mayo de 1917 en las páginas 344-346. 
El segundo artículo del doctor P. Lund "Rayos X en Diagnóstico y tratamiento" fue publicado en Repertorio en junio de $1917 .{ }^{19}$ Un tercer artículo de este autor se refiere al "Diagnóstico de las enfermedades de los huesos por medio de los rayos $\mathrm{X}$ " ${ }^{20}$ Es infortunado que ninguno está ilustrado.

La primera publicación nacional que he encontrado ilustrada con una radiografía de tórax y en la cual se indica (aun cuando en forma vaga) dónde fue tomada, se halla también en el Repertorio de Medicina y Cirugía en un artículo de la autoría de los doctores Guillermo Márquez L. y José M. Montoya titulado: "Pericarditis supurada y pericardiotomía", ${ }^{21}$ con una nota de pie de página en la cual se indica que se trata de una "Observación leída en la Sociedad de Pediatría en su sesión del 12 de noviembre de 1917'. Se refiere a un niño de ocho años de edad quien en junio de ese año sufrió un traumatismo bastante fuerte en la región precordial. "En los días anteriores a su consulta tuvo un resfriado que a los pocos días se complicó con la aparición de fiebre, anorexia, calofríos, malestar general y dolor de costado. Se le diagnosticó neumonía la cual no mejoró con el paso de los días y por el contrario se complicó con la aparición de un levantamiento ligero en la región precordial. Este signo unido a otros hallazgos clínicos llevó a que se pensara en una pericarditis con derrame. Como el abultamiento de la región precordial aumentó, se pensó en pleuresías concomitantes las cuales se descartaron y se concluyó que debía realizarse una pericardiotomía. Previamente a la realización de la misma, 10 días después de la consulta inicial se llevó al niño al laboratorio de rayos $\mathrm{X}$, a donde el Doctor Lund, quien en presencia del doctor Montoya y de algunos alumnos radioscopió (sic) el tórax. El doctor Lund interpretó así la imagen radioscópica: la sombra del corazón y del pericardio es más grande que al estado normal; esta sombra presenta claridades y prolongamientos opacos que permiten sospechar que no es sombra de derrame pleural, pues si esto fuera, su opacidad sería uniforme y estaría a un mismo nivel".

"Se sacó también una radiografía para el museo del laboratorio la cual fue marcada con el número $27 " .{ }^{21}$ En el pie de página de la ilustración de la reproducción fotográfica de la radiografía se lee entre comillas una reproducción del informe del doctor Lund que reza: "La sombra cardíaca agrandada, pudiendo verse fácilmente el abombamiento del lado derecho del pericardio, que indica presencia de líquido en él. Hay también sombra pulmonar en el tercio inferior del lado izquierdo que por no bajar completamente al fondo de la pleura puede considerarse como pleuresía seca 'gota de aceite'. Por la historia de la punción pericárdica considero que se trata de pleuresía secundaria. P.M. LUND” (Figura 10). La interpretación dada: ..."sombra en forma de broche con desaparición de los movimientos rítmicos, sutilmente interpretada por el hábil radiógrafo doctor Lund, apoyó el diagnóstico hecho por los doctores Márquez y Montoya".

Como es conocido, la publicación de nuestro hospital, el Repertorio de Medicina y Cirugía ha sufrido altibajos y en su denominada "segunda época", bajo la dirección del

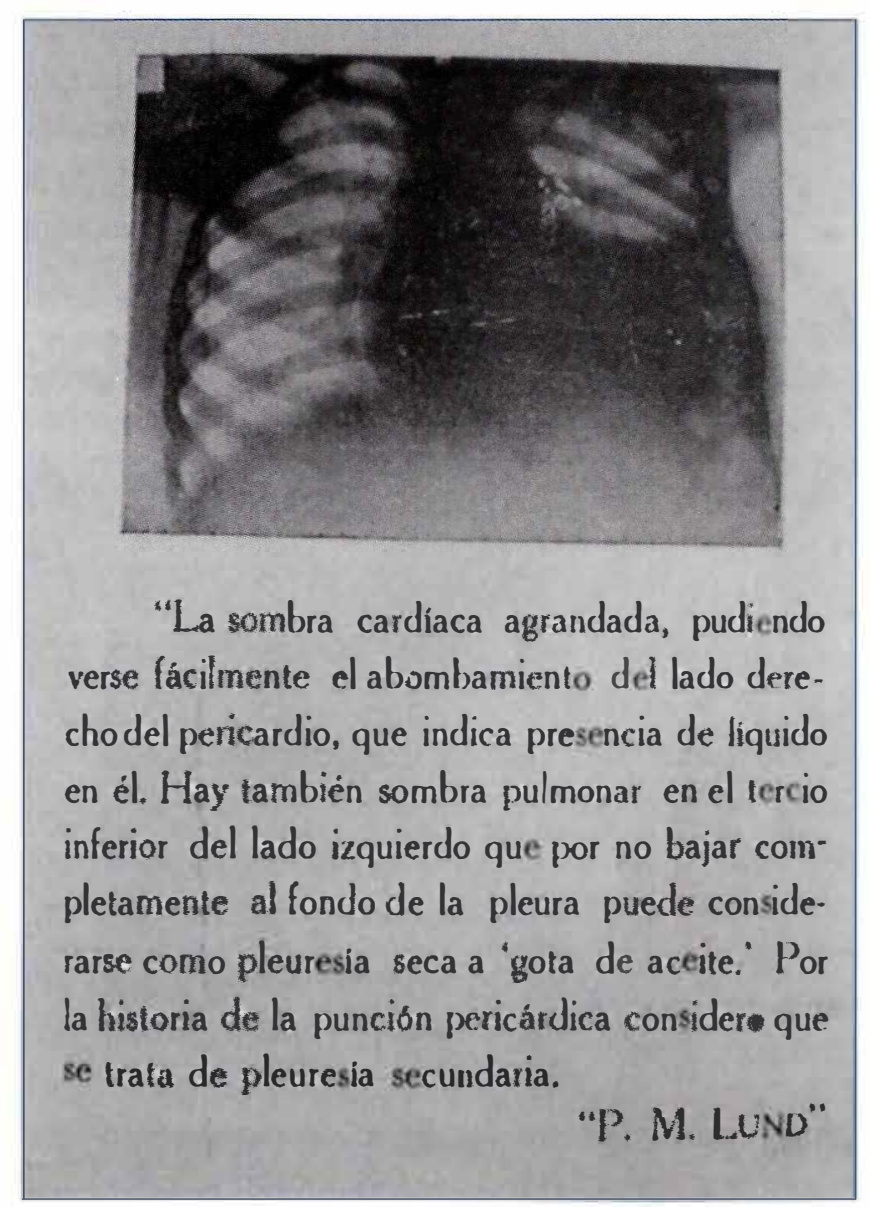

Figura 10. Radiografía del tórax de un niño de ocho años aquejado por pericarditis y derrame pericárdico, y la transcripción del informe del radiólogo el Dr. P.M. Lund. Es la primera radiografía de tórax que aparece publicada en Repertorio de Medicina y Cirugía, Vol.VIII No. II de noviembre de 1917. 
doctor Eduardo Cubides Pardo, hubo numerosos artículos relacionados con patologías diversas en cuyo estudio necesariamente tuvieron que jugar papel destacado los estudios radiológicos, pero no encontramos fotografías aunque se mencionan los controles radiológicos. ${ }^{22}$ En la "terceraépoca” del Repertorio, en 1948 L. Muñozpublica un caso de absceso pulmonar claramente diagnosticado por exámenes clínicomédico de laboratorio y radiográfico pero tampoco está ilustrado. ${ }^{23}$ Juan Di Domenico publica: “Algunas consideraciones sobre gastrectomías" menciona los controles radiológicos obvios en estudios con ingestión de bario pero no hay imágenes. ${ }^{24}$

Si volvemos un poco atrás, veremos que en mayo de 1950 se realizó en el Hospital de San José un Curso de Gastroenterología y se destacó la participación del Departamento de Rayos X con conferencias y demostraciones sobre "Radiología del esófago" y "Radiología del estómago y duodeno", demostraciones prácticas y sesiones de presentación y discusión de radiografías a cargo del doctor Carlos Perilla. Las exposiciones sobre radiología de las vías biliares, colangiografía operatoria y posoperatoria estuvieron a cargo de los doctores Carlos Perilla y Hernando Galvis Ordóñez. ${ }^{25}$

Del 29 de octubre al 3 de noviembre de 1951 con motivo de la Primera Convención Nacional de Cirujanos, se celebraron sesiones en diversos hospitales de la ciudad, entre ellos el nuestro. Del programa científico destacamos dos referentes a la radiología: "Indicaciones del examen radiológico ante sospecha de carcinoma digestivo" de Alberto Torres Focke y la "Comunicación preliminar sobre los primeros casos de angiocardiografía realizados en el Hospital de la Misericordia de Bogotá” de Gonzalo Esguerra Gómez, Calixto Torres Umaña y Santiago Triana. ${ }^{26} \mathrm{El}$ año de 1952 fue pródigo en actividades científicas para el hospital; entre otros se realizó el Primer Curso de Cirugía Cardiovascular para Postgraduados y aun cuando no se hace mención de estudios radiológicos, es imposible suponer que para la época se podía realizar un evento de esta clase sin referirse a ellos. Lo mismo puede decirse del Curso de Laringoscopia y Broncoscopia en el cual uno de los temas era "La tuberculosis broncopulmonar". ${ }^{27}$ Ya para esa época era inconcebible el estudio de la tuberculosis sin el concurso de los rayos $\mathrm{X}$.
Según el doctor L. Muñoz en el personal científico del hospital en 1956 figuraban en radiología el Dr. Marino Barona (jefe), Marco F. Bulla, Francisco Mosser y Benjamín Tavera. ${ }^{28}$ Fruto de todos estos años de maduración fueron los cursos de imágenes diagnósticas realizados en el renovado auditorio G. Fergusson de nuestro hospital los días 5 y 6 de julio de 2002 en el marco del II Encuentro de Egresados del Servicio y de las celebraciones de la conmemoración del centenario de la fundación de la Sociedad de Cirugía de Bogotá, curso que incluyó una videoconferencia, quizá de las primeras realizadas en el país con participación los doctores A. Romero J. (egresado del servicio) y M. Maynard, profesor de las universidades de Gran Canaria y Lousiana State University en Estados Unidos, desde la ciudad de Barcelona (España); y el realizado en 2004 con participación de radiólogos formados en nuestro servicio que laboran en diversas instituciones nacionales y del exterior quienes como ya dijimos dan brillo y prestigio no solamente a la radiología colombiana en general sino a nuestro hospital. Eventos similares se repitieron en los años 2002, 2003 y 2007.

Así, tal y como lo atestigua la participación meritoria y laureada de los integrantes del servicio en diversos congresos y eventos académicos y gremiales, el servicio de Imágenes Diagnósticas fiel a su tradición sigue siendo y será por muchos años parte integral importante en la vida de nuestro Hospital de San José.

\section{Referencias}

1. Muñoz, L. Historia del Hospital de San José 1902-1956. Bogota : Banco de la República, 1958.

2. Gómez Cusnir J. La Sociedad de Cirugía de Bogotá y la salud en Colombia. Repert med cir : edición especial Centenario Sociedad de Cirugía de Bogotá Hospital de San José, 1902-2002. 2002. p. 11-13

3. Sociedad de Cirugía de Bogotá. Itinerario histórico desde el 22 de julio de 1902. Santafé de Bogotá : Sociedad de Cirugia de Bogota, 1997. p. 10.

4. Muñoz, L. Historia del Hospital de San José 1902-1956. Bogota : Banco de la República, 1958. p. 314

5. Sociedad de Cirugía de Bogotá Itinerario Histórico desde el 22 de julio de 1902. Santafé de Bogotá : Sociedad de Cirugía de Bogotá; 1997. p. 81- 82

6. Muñoz, L. Historia del Hospital de San José 1902-1956. Bogotá: Banco de la República, 1958. p. 315

7. Muñoz, L. Historia del Hospital de San José 1902-1956. Bogotá: Banco de la República, 1958. p. 384 
8. Muñoz, L. Historia del Hospital de San José 1902-1956. Bogotá: Banco de la República, 1958. p. 322

9. Muñoz, L. Historia del Hospital de San José 1902-1956. Bogotá: Banco de la República, 1958. p. 383.

10. Montoya, JM. El Hospital de San José. Repertorio de Medicina y Cirugía. 1925; 16(5): p. 229

11. Muñoz, L. Historia del Hospital de San José 1902-1956. Bogotá: Banco de la República, 1958. p. 384.

12. Acero G. Gonzalo Esguerra Gómez: ¡un precursor de la radiología!. El Informador Médico. 1995; 9(52):18

13. Muñoz, L. Historia del Hospital de San José 1902-1956. Bogotá: Banco de la República, 1958. p. 377

14. Muñoz, L. Historia del Hospital de San José 1902-1956. Bogotá: Banco de la República, 1958.p. 385

15. Suárez JJ. Sinopsis histórica del Servicio de Rayos X del Hospital de San José. Rev. Col M de N.S. del Rosario, 1993 mar; 559: 108-10.

16. Buckner HT. Tratamiento de las fracturas complicadas del húmero y del fémur por medio de nuevos aparatos. Rep Med Cir. 1917; 8(11): 521

17. Lund, Peer M. Valor de los Rayos X en terapéutica y como elementos para el diagnóstico. Rep Med Cir. 1917; 8(8): 344-46.
18. Ulloa, LH. El Departamento de imágenes diagnósticas de la Facultad de Medicina de la Universidad Nacional de Colombia. Rev Colomb Radiol. 2008; 19:(2):2355-6.

19. Lund, Peer M. Rayos X en diagnóstico y tratamiento. Rep Med Cir. 1917; 8(9): 389-94.

20. Lund, Peer M. Diagnóstico de las enfermedades de los huesos por medio de los rayos X. Rep Med Cir. 1917; 9(1): 44

21. Márquez G, Montoya JM. Pericarditis supurada y pericardiotomía. Rep Med Cir. 1917; 9(3):115-26.

22. Muñoz L. Historia del Hospital de San José 1902-1956. Bogotá: Banco de la República, 1958. p. 361.

23. Muñoz L. Absceso pulmonar. Rep Med Cir. 1948; 8(3): 606-13.

24. Muñoz L. Historia del Hospital de San José 1902-1956. Bogotá: Banco de la República, 1958. p. 396.

25. Muñoz L. Historia del Hospital de San José 1902-1956. Bogotá: Banco de la República, 1958. p. 423.

26. Muñoz L. Historia del Hospital de San José 1902-1956. Bogotá: Banco de la República, 1958. p. 435.

27. Muñoz L. Historia del Hospital de San José 1902-1956. Bogotá: Banco de la República, 1958. p. 443

28. Muñoz L. Historia del Hospital de San José 1902-1956. Bogotá: Banco de la República, 1958. p. 454 